\title{
OVERVIEW OF PALLIATIVE CARE SERVICE IN HONG KONG
}

\author{
Hilary H.L Yeel, Ben Y.F Fong'2, Tommy K.C Ng' \\ 1. School of Professional Education and Executive Development, The Hong Kong Polytechnic University \\ 2. College of Professional and Continuing Education, The Hong Kong Polytechnic University
}

Correspondence: hilary.yee@speed-polyu.edu.hk

\begin{abstract}
Palliative care service is a growing trend for patients with terminal illnesses. The purpose of palliative care is to improve the quality of life for the patients and their family by providing comprehensive care such as symptoms control, pain relief and counselling support. More and more people prefer to spend the final stage of their life in a comfortable environment with adequate care. However, Hong Kong is only ranked 22 in 2015 Quality of Death Index, and hence enhancement of palliative care service is much needed. This review paper aims to evaluate the current resources and development of palliative care service in Hong Kong and suggest improvement of the service. This study reveals that the system in Hong Kong lacks a comprehensive policy, thus limiting organisations to provide the service to small-scale operations and resulting in fragmentation of the co-operation between the public and private sectors. Factors such as professional training, community engagement, culture and financial issues are affecting the development and adequacy of palliative care service.
\end{abstract}

\section{KEYWORDS}

palliative care; quality of life; Quality of Death Index; palliative care guideline; government policy; end of life issues

\section{INTRODUCTION}

The World Health Organization (WHO) defines palliative care service as:

\begin{abstract}
'an approach that improves the quality of life of patients, both adults and children, and their families facing the problems associated with lifethreatening illnesses through the prevention and relief of suffering by means of early identification impeccable assessment, and treatment of pain and other problems, physical, psychosocial, or spiritual.' [1]
\end{abstract}

One of the most widely known life-threatening illnesses is cancer. There were around 30,000 new cancer cases in Hong Kong in 2016, which was an increase of $3 \%$ as compared with the previous year, [2] Apart from the conventional treatments like radiotherapy and chemotherapy in cancers, palliative care is an approach to manage symptoms and side effects of cancers and their treatments. According to the statistics from the Hospital Authority (HA) of Hong Kong, around $68 \%$ of cancer patients had received palliative care before death in 20122013. Often, the service is offered as soon as cancer is diagnosed, during cancer treatment or continued after treatment. [3]

In addition to cancer patients, palliative care also covers patients who suffer from other serious illnesses such as Parkinson's disease, dementia and chronic life-limiting diseases such as cardiovascular diseases, chronic respiratory diseases or AIDS, [4] In Hong Kong, 44\% of 
patients with end-stage renal failure have received palliative care. [3] Based on individual's needs, palliative care services may include pain relief, management of distressing symptoms like vomiting and shortness of breath, emotional support and counselling for both patients and their families, and helping them to explore their beliefs and values. It is a team approach to find out the needs of patients and their families and offer a support system to improve their quality of life when facing problems associated with life-limiting and terminal illnesses. [1] In addition to clinical care, the professional team provides psychological, emotional, and social care, and thus palliative care is called supportive care or comfort care.

\section{RESOURCES OF PALLIATIVE CARE SERVICES IN HONG KONG}

\section{HOSPICE BEDS}

Currently, there are approximately 360 hospice beds available in 16 hospitals under the HA that provide comprehensive palliative care such as symptom control and psychological counselling for terminally ill patients and their family. [3] Based on the total population of 7.41 million in 2017 [5], there are around 4.8 in-patient hospice beds per 100,000 of the Hong Kong population. Non-government organisations (NGOs) such as the Haven of Hope Christian Service (HOHCS), Hong Kong Anti-Cancer Society (HKACS) and Society for the Promotion of Hospice Care (SPHC) also provide hospice care services. HOHCS provides 124 beds for palliative and hospice care services, while the Jockey Club Home for Hospice ( $\mathrm{JCHH}$ ) offers 30 part-public and part-private beds under SPHC. The Hong Kong Anti-Cancer Society Jockey Club Cancer Rehabilitation Centre (JCCRC) provides 180 beds to cancer patients or seriously ill patients. [6]

\section{HUMAN RESOURCES}

There were around 300 nurses engaged in the provision of palliative care up to 2011 [7]. As palliative care is not a compulsory module in the nursing courses, nurses who are interested in working in this field need to take postgraduate courses or diplomas. They include a specialty nursing programme in palliative care provided by the Hospital Authority Institute of Advanced Nursing Studies, a diploma in oncology and palliative care for healthcare professionals, a higher diploma in community healthcare for senior citizens. There are also some structured palliative care training workshops provided to nurses as well as other healthcare workers by institutions such as the HKACS, SPHC and the Federation of Medical Societies of Hong Kong. [8] There are 49 specialist palliative care physicians in Hong Kong. [9] There are currently only 22 registered specialists in palliative medicine which is a subspecialty of medicine. [10] Since 2012, clinical psychologists and medical social workers are also included in the public healthcare sector to promote a multidisciplinary palliative care team and to support the psychosocial needs of patients and their families. [11]

\section{TYPES OF PALLIATIVE CARE}

There are mainly four types of palliative care including, inpatient, outpatient, home and day care. Inpatient palliative care is suitable for patients with moderate to serious or unstable symptoms. They require daily treatments, most often at hospitals, medical centres or nursing homes. Some patients who are suffering from late stage diseases will have rehabilitation treatment to maintain their daily living activities. For patients who are staying in an acute unit, doctors and nurses from the palliative consultative team will visit them regularly to provide consultation and support. [12]

Outpatient care is suitable for stable and discharged patients. Patients who are in late stage with specialty treatment or psychological issues are normally referred to outpatient care clinics. [12]

Home care assists patients who are weak and unable to attend follow-up care in the outpatient clinic. The home care team will go to the patients' home to care for them and to monitor their health conditions. They may also help patients and their family and relatives to plan and prepare the death at their home. The team will stand by and counsel families and relatives before and after the patients' death to manage psychological breakdown during the whole process. [12]

Day care is suitable for patients who are stable and require monitoring every day. It provides the patients social activities and group or individual psychological counselling service to improve their quality of life. Usually, there is a resource centre in the day care service that provides education material to family and relatives and, medical equipment for patients to use. [12] 


\section{END-OF-LIFE SERVICES}

End-of-life (EOL) care is an integral part of palliative care and is the provision of care and support for patients who are approaching death. The Social Welfare Department (SWD) of the Hong Kong Government has been adjusting the subsidy amount for contract residential care homes for elderly (RCHEs) and requires them to integrate EOL care into their care services on palliative care. [13] SWD aims to have all contract RCHEs providing EOL care services by the end of 2019-20. [14]

As palliative care service is mainly provided by HA, it has supported the development of palliative care by issuing different guidelines, including guidance for clinicians on advance directives in adults in 2010, do-not-attempt cardiopulmonary resuscitation (DNACPR) in 2014 and guidelines on life-sustaining treatments in the terminally ill in 2015. In addition, the Hong Kong west community geriatric assessment team of the HA has initiated an EOL pilot programme for the RCHEs, in cooperation with the Tung Wah Group of Hospitals Jockey Club Care and Attention Home since 2009. [15] The programme provides opportunities for RCHE staff to receive palliative care training in Taiwan and has shown in return a reduction of acute hospital admissions of their patients.

In order to have a multidisciplinary team for palliative care, HA has continued to offer more education and training programmes for health professionals in general hospital wards, staff in home care, and professional societies in recent years in order to equip them with better skills and knowledge in palliative care. [11] Since 2012, a funding of around $\$ 12$ million per year has been initiated by HA to recruit clinical psychologists and medical social workers in the public healthcare sector, with the aim of addressing the psychosocial needs of patients and their family.

\section{ADVANCE DIRECTIVE POLICY}

Advance directive (AD) is a legal statement, usually in writing, in which a person has signed in advance to indicate the kind of healthcare he or she would like, if he or she would wish to have extraordinary life-sustaining treatment to prolong life in the future. The purpose of setting an $A D$ is to safeguard a person's will and preference for future medical or personal care when he or she is no longer mentally competent. [16,8] It also aims to benefit people in receiving appropriate palliative care services and improve their quality of life. $A D$ should be made voluntary and optional to all individuals.
The concept of advance directive has been promoted in a non-legislative approach under the existing common law framework since the report made by Law Reform Commission of Hong Kong in 2006. [8] Hong Kong currently relies on the common law framework and the Strategic Service Framework for Palliative Care made by the HA [3] to carry out advance care planning (ACP) and a valid $A D$ with patient's consent to receiving health treatment. Due to the legal uncertainties, health professionals are under difficult situations to follow or unfollow an $A D$ which may create conflicts with patient's will and right to refuse treatment. Therefore, the Hong Kong Government launched a public consultation in September 2019 to solicit the opinion of the public on legislation of $A D$ and dying in place.

\section{POLICY RECOMMENDATIONS}

\section{TO ESTABLISH A GUIDELINE TO ASSESS THE NEEDS OF PALLIATIVE CARE}

Apart from stepping up the effort in legalising AD after the public consultation, a guideline with criteria assessment is also needed to facilitate the medical team to screen patients for unmet palliative care in advance. Two assessment guidelines, assessment at the time of admission and assessment during day hospital should be developed. [17] Both guidelines should be divided into primary and secondary criteria to screen patients at basic needs and high likelihood of palliative care needs respectively. In assessment during the admission, the primary criteria should assess patients' frequency of admissions to the hospital, complexity of the care requirements, decline in body function and so on, while the secondary criteria should assess the age of patients, their admission from long-term care facility, cognition condition, availability of social support, chronic disease and so on. During the hospital stay, primary criteria should include difficulty of controlling physical or psychological symptoms, length of staying in intensive care unit, disagreements or uncertainty among patients, staff etc. For secondary criteria, transplantation of solid-organ, emotional or spiritual distress of patients, family should be assessed. With a well-developed guideline, the medical team can respond effectively upon identification of issues and initiate referrals to doctors specialised in palliative care for further consultation. Thus, the patients can benefit from adequate management of pain and symptoms, and emotional, spiritual and social issues in advance. 


\section{EXPANDING PROFESSIONAL EDUCATION AND TRAINING}

Education on palliative care curriculum should be expanded and made compulsory in the training of health professionals. Currently education opportunity in palliative care is limited to the diploma and workshops provided by the University of Hong Kong School of Professional and Continuing Education and School of Continuing and Professional Studies of The Chinese University of Hong Kong. For nurses, apart from certificate programmes provided by the Hong Kong College of Gerontology Nursing and Hong Kong Association of Gerontology, more certification programs for both hospice and palliative care nurses should be provided. The Hong Kong government should enable nurses to be formally registered as specialised nurses in palliative care instead of being diploma and certificate holders. These measures will increase the incentives for professionals to work and develop in this field and to position themselves in their career.

There should be on-the-job training courses on improving communication skills and how to handle the topic of death with sensitivity. Doctors, nurses, social workers and other staff in hospitals should discuss EOL issues and palliative care service with patients and their family members during early hospitalisation period, but not at the very late stage of illness. They should be trained to identify the right timing to initiate referral to avoid any delay and to explain the care and treatment options clearly to patients and their family. In particular, such training should be promoted to specialties and units that are not interested in, or have a low awareness or inadequate knowledge on palliative and EOL care.

\section{IMPROVING PUBLIC KNOWLEDGE AND EDUCATION}

To clarify the concept of palliative care service and to avoid misunderstanding, the government should actively promote palliative care service to the public through regular talks, workshops and seminars in the community, and through the social media. In local hospitals, eyecatching posters and leaflets about palliative care services should be displayed in order to let patients and their relatives obtain, understand and use information of the service. On the other hand, family members of patients often play an active role in making health-related decisions including medical treatment as they would want to prolong a patient's life. There are patients who would rather refuse discussing future care with family members to avoid tension.
Through education at schools and community activities, students and the public can learn how to respect the wish and preference on medical treatment of the patients as some of whom may not want others to make the decision for them based on their own value. People can also learn to accept death as part of life and the ways to choose the most suitable heath care services. To encourage more people to talk about death and bereavement in the society, organising 'Death Cafes' can allow participants to freely voice out their views and concerns over death with one another. Moreover, talks about different cultural perspectives on death can also educate the public to have a wider view on death.

\section{INCREASING FUNDING ON PALLIATIVE CARE SERVICE}

Since expenditure on public and private health care in the Hong Kong is only about $5.8 \%$ of the Gross Domestic Product (GDP) in 2017/2018 (Hong Kong's Domestic health Accounts, 2019), compared to other countries like Japan (10.7\% of GDP) and United Kingdom (9.6\% of GDP), the proportion for palliative and EOL care expenditure is relatively limited. Palliative care and EOL investment should be a policy priority. The government should provide sufficient funding on palliative care service by increasing the supply of specialists and facilities such as hospices and RCHEs.

A department responsible for palliative care in public and private hospitals should be setup to manage patients' referrals and communication between different healthcare and social services sectors. In addition, equipment such as vehicles and medical instruments for patient transferal service should also be provided. Palliative care service should not only rely on the provision by HA but should be widely expanded to include NGOs and the private sector. Instead of one-off funding, continuous funding and charity programme to NGOs can support them to provide sustainable service in the community as well as designing a caring environment in patients' wards and arranging more home visits by care providers.

\section{RESEARCH ON PALLIATIVE CARE}

Research incentive is another area to be improved in palliative care. Research related to effects and impacts of palliative and EOL care services on patients and their family members have always been limited. Local data are important as findings from other countries may not be 
applicable or culturally appropriate to Hong Kong. Therefore, the government should provide research funding schemes and facilitate the setup of research centres in order to analyse the demand and supply of palliative care, and facilitate new and innovative interventions to improve the quality of service.

\section{CONCLUSION}

Palliative care service in Hong Kong is becoming more comprehensive and diverse. However, Hong Kong is only positioned at 22 in the 2015 Quality of Death (QOD) Index. [18] When comparing with other developed eastern economies such as Taiwan, Japan and Korea, Hong Kong is still lagging behind in meeting the international standard in palliative care. As reported in the 2015 QOD Index by Economist Intelligence Unit, Hong Kong was at low positions in terms of spending on healthcare and policy evaluation, and the capacity to deliver palliative care services, and public awareness of palliative care. With the growing ageing population and prevalence of chronic diseases, there is a service need to develop long-term care planning in palliative care involving the government, hospitals, hospices, palliative specialists and the community.

The most recent public consultation concerning EOL legislative proposals launched by The Food and Health Bureau (FHB) is to revise the current common law position in respect of $A D$. With a more comprehensive legislation on $A D$, conflicting regulations can be avoided and patients' right and interest on dying in place can be respected. The amendment of AD can also help to give an impetus on the development of more palliative day care centres, hospices and even palliative care home service as people may decide to remain at home when approaching their EOL.

The School of Professional Education and Executive Education of The Hong Kong Polytechnic University began to offer a new elective subject of "End of Life Issues" to the final year top-up undergraduate programme in Health Studies in the academic year of 2018-2019. The subject has attracted the interest and attention of the students, who presented their projects at the Research Seminar at the Jockey Club Home for Hospice in April 2019.

\section{ACKNOWLEDGEMENT}

The work described in this paper was fully supported by a grant from the Research Grants Council of the Hong Kong Special Administrative Region, China (Project Reference No.: UGC/IDS24/18).

\section{References}

1. World Health Organization. WHO Definition of Palliative Care. [Internet]. [cited 1 December 2019] Available from:

https://www.who.int/cancer/palliative/definition/en/

2. Hong Kong Cancer Registry. Overview of Hong Kong Cancer Statistics of 2016. [Internet]. 2018 [cited 20 August 2019]. Available from: https://www3.ha.org.hk/cancereg/pdf/overview/Sum mary\%20of\%20CanStat\%202016.pdf

3. Hospital Authority. Strategic Service Framework for Palliative Care. [Internet]. 2017. [cited 20 August 2019] Available from: http://www.ha.org.hk/haho/ho/ap/PCSSF_1.pdf

4. World Health Organization. Planning and Implementing Palliative Care Service: A Guide For Programme Managers. [Internet]. 2016. [cited 20 August 2019] Available from: https://apps.who.int/iris/bitstream/handle/10665/2505 84/9789241565417-

eng.pdf;jsessionid=E6C 40393B5A9B320F8E91 18C0CD05 570 ? sequence $=1$

5. Census and Statistics Department. Population estimates. [Internet]. [updated 2019, cited 10 December 2019]. Available from https://www.censtatd.gov.hk/hkstat/sub/sp150.jsp?ta blelD $=001 \& \mid \mathrm{D}=0$ \& productType $=8$

6. The D. H. Chen Foundation. Supporting Palliative and Hospice Care Services in Hong Kong. [Internet]. 2015 [cited 12 December 2019]. Available from: https://dhchenfoundation.com/initiatives/supportingpalliative-and hospice-care-services-in-hong-kong/

7. Chan HYL, Lee, DTF, Woo N, Yi H. A Study on the Development of Palliative and End-of-Life Care Services in Hong Kong. [Internet]. 2017. [cited 10 December 2019]. Available from: https://www.pico.gov.hk/doc/en/research_report(PDF //2016_A4_022_16C_Final_eport_Prof_Chan.pdf 
8. Food and Health Bureau, The Hong Kong Special Administrative Region Government. Public consultation on End-of-Life Care legislative proposals launched (with video). [Internet]. 2019. [cited 19 November 2019] Available from https://www.info.gov.hk/gia/general/201909/06/P2019 090500543.htm

9. Yamaguchi T, Kuriya M, Morita T, Agar M, Choi YS, Goh C, Lingegowda KB, Lim R, Liu RK, MacLeod R, Ocampo R. Palliative care development in the Asia-Pacific region: an international survey from the Asia Pacific Hospice Palliative Care Network (APHN). BMJ supportive \& palliative care. 2017; 7(1), 23-31.

10. The Medical Council of Hong Kong. Licensing Examination. [Internet]. 2018. [cited 20 December 2019] Available from: https://leip.mchk.org.hk/EN/dexam_Ill.html

11. Legislative Council. Palliative care services for terminally ill patients. [Internet]. 2016. [cited 10 December 2019] Available from: http://www.info.gov.hk/gia/general/201603/16/P2016 03160553.htm

12. Hospital Authority. Referral Criteria for Different Palliative Care Type for Advanced Progressive Disease. [Internet]. 2015. [cited 11 December 2019] Available from: https://www.ha.org.hk/haho/ho/hacp/121580e.pdf

13. Legislative Council. Joint subcommittee on long-term care policy - hospice care services. [Internet]. 2014. [cited 12 December 2019]. Available from: http://www.legco.gov.hk/yr1314/english/panels/ltcp/papers/ltcp0624cb2-1820-1e.pdf

14. Legislative Council. Joint Subcommittee on Long-term Care Policy. [Internet]. 2017. [cited 12 December 2019] Available from: https://www.legco.gov.hk/yr1718/english/panels/ltcp/papers/ltcp20171212cb2-4762-e.pdf

15. Luk JKH, Liu A, Beh P, Chan FHW. End-of-life care in Hong Kong. Asian Journal of Gerontology \& Geriatrics. $2011 ; 6,103-106$.

16. Singapore Legal Advice. Advance Medical Directives in Singapore. [Internet]. [updated 2019, cited 12 December 2019] Available from: https://singaporelegaladvice.com/lawarticles/advance-medical-directives-in-singapore/
17. Weissman DE, Meier DE. Identifying patients in need of a palliative care assessment in the hospital setting a consensus report from the Center to Advance Palliative Care. Journal of palliative medicine. $2011 ; 14(1), 17-23$.

18. Economist Intelligence Unit. The 2015 Quality of Death Index Ranking palliative care across the world. Econ. 2015 Aug:71. 